\section{Assessing Fatty Acid Profiles of Macadamia Nuts}

\author{
Tim J. O'Hare ${ }^{1}$ and Hung Hong Trieu \\ Queensland Alliance for Agricultural and Food Innovation, University of \\ Queensland, Coopers Plains 4108, Queensland, Australia
}

\author{
Bruce Topp \\ Queensland Alliance for Agricultural and Food Innovation, University of \\ Queensland, Nambour 4560, Queensland, Australia
}

\section{Dougal Russell \\ Department of Agriculture and Fisheries, Nambour 4560, Queensland, Australia \\ Sharon Pun, Caterina Torrisi, and Dianna Liu \\ Department of Agriculture and Fisheries, Coopers Plains 4108, Queensland, Australia}

Additional index words. palmitic, stearic, palmitoleic, oleic, cardiovascular disease, monounsaturated, fatty acid

\begin{abstract}
The kernel of the macadamia nut (Macadamia integrifolia and M. tetraphylla) is very high in oil, accounting for about three -quarters of their mass. In the current investigation, oil extracts from 20 breeding accessions and 14 cultivars had a range of $12.3 \%$ to $17.0 \%$ saturated fat, averaging $14.2 \%$. Although all samples were found to be very high in "healthy" monounsaturated fats, the level of saturated fat slightly exceeds that of many other nuts that are able to make qualified health claims. The lowest saturated fat content $(12.3 \%)$ corresponded to $4.6 \mathrm{~g}$ saturated fat $/ 50 \mathrm{~g}$ kernels, which was slightly greater than the $4.0 \mathrm{~g}$ maximum. Despite this, potential exists to develop a reduced-saturated fat macadamia by combining characteristics found in different lines. The current trial indicates that lower total saturated fat was associated with a stronger ability to partition $\mathrm{C} 16$ and $\mathrm{C} 18$ fats to their monounsaturated fatty acids, or to elongate C16:0 to C18:0 and subsequently desaturate C18:0 to C18:1. It was also observed that the pollinizer parent is likely to have an influence on saturated fat content, although this would need to be confirmed in controlled pollination trials. Macadamia varieties generally outcross, and because the edible kernel (embryo) is formed from a pollinated ovule, it is likely any future reduced-saturated fat line would also require a reducedsaturated fat pollinizer parent.
\end{abstract}

Macadamia nut kernels (Macadamia integrifolia, $M$. tetraphylla 2 are very high in oil, accounting for about three-quarters of their weight (Saleeb et al., 1973). The oil itself consists of $\approx 77 \%$ to $80 \%$ monounsaturated fat, $1 \%$ to $7 \%$ polyunsaturated fat, and the remaining $14 \%$ to $21 \%$ saturated fat (Aquino-Bolaños et al., 2017; Beuchat and Worthington, 1978; Carrillo et al., 2017; Cavaletto et al., 1966; Saleeb et al., 1973). Although unsaturated fats are considered "good" for cardiovascular health, there is a general consensus that saturated fats are detrimental (Clifton and Keogh, 2017; Sacks et al., 2017; Wang and $\mathrm{Hu}, 2017$ ). And although the majority of fats in macadamia are "good," the level of saturated fat present

Received for publication 24 Aug. 2018. Accepted for publication 16 Sept. 2018.

This paper was presented as a part of the 2017 International Macadamia Research Symposium, 13-14 Sept. 2017, Big Island, HI.

${ }^{1}$ Corresponding author. E-mail: t.ohare@uq.edu. au.
The following investigation explores the variability in fatty acid profiles of a range of commercial cultivars and accessions in the Australian macadamia nut breeding program. The aim of this analysis was to identify the existence of reduced-saturated fat varieties, or accessions that may have potential as prospective parents for breeding a low- or a reduced-saturated fat variety. Because saturated fatty acids are the precursors of monoand polyunsaturated fatty acids, accessions with greater unsaturated-to-saturated fatty acid ratios may further serve as a useful starting point for producing a variety with both reduced saturated fat and greater unsaturated fat.

\section{Materials and Methods}

Fourteen cultivars and 20 breeding accessions from the Australian macadamia breeding program were harvested at commercial maturity from the Tiaro (Queensland) germplasm collection in 2016. The pollination parent was uncontrolled and, when possible, nuts were harvested from two different trees of each line, spaced as distant as possible from each other within the germplasm collection. All trees were grown under the same fertilizer and irrigation regimes on a uniform soil type.

The nuts were dehusked and dried in an incubator $\left(35^{\circ} \mathrm{C}\right.$ for $2 \mathrm{~d}, 45^{\circ} \mathrm{C}$ for $2 \mathrm{~d}, 55^{\circ} \mathrm{C}$ for $2 \mathrm{~d}$ ) to $\approx 1 \%$ to $2 \%$ moisture content. Nuts were hand-cracked, and five kernels were selected randomly for oil extraction. Oil was extracted with a hydraulic press operated at $24{ }^{\circ} \mathrm{C}$. Approximately $3 \mathrm{~mL}$ oil was collected as a composite sample. Approximately $0.1 \mathrm{~g}$ oil was dissolved in $1.6 \mathrm{~mL}$ hexane before adding $100 \mu \mathrm{L} 2 \mathrm{M}$ methanolic $\mathrm{KOH}$. The mixture was shaken for $30 \mathrm{~s}$ and then centrifuged at $960 g_{\mathrm{n}}$ for $2 \mathrm{~min}$. The hexane layer was collected and filtered for gas chromatography-mass spectrometry analysis. One microliter of the filtered hexane layer was injected into a Shimadzu GC-MS system (Shimadzu, Kyoto, Japan), consisting of a gas chromatograph (Shimadzu GC-2010 Plus) coupled with a mass spectrometer (Shimadzu MS-TQ8040) using a Shimadzu AOC 6000 autosampler. The gas chromatograph was fitted with an Rtx-5MS column (length, $30 \mathrm{~m}$; thickness, $0.25 \mu \mathrm{m}$; diameter, $0.25 \mathrm{~mm}$ ) (Restek, Bellefonte, PA). The injector was held at $240{ }^{\circ} \mathrm{C}$. The column oven was held at $80^{\circ} \mathrm{C}$ for $1 \mathrm{~min}$, then increased to $150{ }^{\circ} \mathrm{C}$ at a rate of $30{ }^{\circ} \mathrm{C} / \mathrm{min}$. The column temperature was then increased to $180^{\circ} \mathrm{C}$ at a rate of $4{ }^{\circ} \mathrm{C} / \mathrm{min}$, and then increased to $280{ }^{\circ} \mathrm{C}$ at a rate of $3{ }^{\circ} \mathrm{C} / \mathrm{min}$. Column flow rate was $1.34 \mathrm{~mL} / \mathrm{min}$, total flow rate was $193.9 \mathrm{~mL} / \mathrm{min}$, and the split ratio was 140.0 . The carrier gas was nitrogen (high purity) and the column pressure $91.3 \mathrm{kPa}$. Fatty acid methyl esters were identified by comparison of retention time, molecular mass, and fragment ions. Oil concentration was determined as a percentage of total oil based on the ratio of individual peak area to total peak area, using data processing software (Labsolutions Insight software, Version 3.2, Shimadzu Oceania, Sydney, Australia). 


\begin{tabular}{|c|c|c|c|c|c|c|c|c|c|c|c|c|c|c|c|c|}
\hline \multirow[b]{2}{*}{ Cultivar } & \multicolumn{12}{|c|}{ Fatty acid (\%) } & \multirow[b]{2}{*}{ Total sat-fat (\%) } & \multirow[b]{2}{*}{ C18-desat } & \multirow[b]{2}{*}{ C16-desat } & \multirow[b]{2}{*}{ C16-elong } \\
\hline & $\mathrm{Cl2}: 0$ & $\mathrm{C} 14: 0$ & C16:0 & C16:1 & C18:0 & C18:1 & C18:2 & $\mathrm{C} 18: 3$ & $\mathrm{C} 20: 0$ & $\mathrm{C} 20: 1$ & $\mathrm{C} 22: 0$ & $\mathrm{C} 22: 1$ & & & & \\
\hline A16-1 & 0.0 & 0.6 & 7.6 & 19.5 & 1.9 & 64.2 & 2.1 & 0.1 & 1.7 & 1.6 & 0.5 & 0.1 & 12.4 & 16.3 & 0.24 & 2.7 \\
\hline A376-2 & 0.0 & 0.6 & 7.6 & 24.0 & 2.2 & 59.5 & 2.1 & 0.1 & 1.7 & 1.8 & 0.3 & 0.1 & 12.5 & 14.9 & 0.32 & 2.1 \\
\hline A376-1 & 0.0 & 0.5 & 7.2 & 20.4 & 2.8 & 62.8 & 1.9 & 0.1 & 2.1 & 1.7 & 0.3 & 0.1 & 13.0 & 12.7 & 0.26 & 2.6 \\
\hline A447-2 & 0.1 & 0.6 & 8.1 & 21.8 & 2.6 & 61.5 & 1.4 & 0.1 & 1.9 & 1.7 & 0.2 & 0.1 & 13.5 & 13.9 & 0.28 & 2.3 \\
\hline A447-1 & 0.1 & 0.8 & 8.4 & 20.8 & 2.1 & 62.8 & 1.4 & 0.1 & 1.9 & 1.3 & 0.3 & 0.0 & 13.5 & 15.4 & 0.27 & 2.4 \\
\hline A403-1 & 0.1 & 0.7 & 8.2 & 23.0 & 2.4 & 59.2 & 1.8 & 0.1 & 2.0 & 2.2 & 0.3 & 0.1 & 13.6 & 13.7 & 0.30 & 2.2 \\
\hline HAES791 & 0.0 & 0.4 & 7.1 & 18.1 & 3.4 & 64.7 & 1.6 & 0.1 & 2.3 & 1.8 & 0.3 & 0.1 & 13.6 & 11.3 & 0.22 & 2.9 \\
\hline HAES344-2 & 0.2 & 1.3 & 7.6 & 19.7 & 2.3 & 63.3 & 1.5 & 0.1 & 1.7 & 1.6 & 0.5 & 0.1 & 13.6 & 14.8 & 0.25 & 2.6 \\
\hline A538-2 & 0.1 & 0.7 & 8.3 & 16.6 & 2.3 & 66.0 & 1.7 & 0.1 & 2.0 & 1.9 & 0.3 & 0.1 & 13.7 & 15.0 & 0.20 & 3.0 \\
\hline A403-2 & 0.1 & 0.6 & 8.0 & 19.4 & 2.7 & 63.9 & 1.4 & 0.1 & 1.9 & 1.5 & 0.4 & 0.1 & 13.7 & 13.3 & 0.24 & 2.6 \\
\hline HAES741-2 & 0.1 & 1.1 & 7.1 & 19.4 & 3.3 & 63.6 & 1.4 & 0.1 & 2.0 & 1.6 & 0.2 & 0.1 & 13.9 & 11.9 & 0.24 & 2.7 \\
\hline A422-2 & 0.1 & 0.7 & 8.0 & 17.1 & 2.6 & 64.5 & 1.7 & 0.1 & 2.2 & 2.5 & 0.5 & 0.2 & 14.0 & 12.9 & 0.21 & 3.0 \\
\hline A422-1 & 0.1 & 1.1 & 8.1 & 18.0 & 2.7 & 64.3 & 1.7 & 0.1 & 2.0 & 1.7 & 0.2 & 0.0 & 14.1 & 13.9 & 0.22 & 2.8 \\
\hline HAES741-1 & 0.1 & 1.2 & 7.9 & 21.8 & 3.1 & 61.0 & 1.4 & 0.1 & 1.9 & 1.4 & 0.2 & 0.0 & 14.3 & 12.4 & 0.28 & 2.3 \\
\hline Beaumont & 0.1 & 0.6 & 9.3 & 22.6 & 2.5 & 58.6 & 2.4 & 0.1 & 1.7 & 1.7 & 0.3 & 0.1 & 14.4 & 14.1 & 0.29 & 2.1 \\
\hline HAES816-2 & 0.1 & 0.9 & 9.0 & 19.7 & 2.2 & 62.3 & 1.6 & 0.1 & 1.8 & 1.7 & 0.6 & 0.1 & 14.5 & 14.5 & 0.25 & 2.5 \\
\hline HAES816-1 & 0.1 & 0.8 & 8.4 & 16.7 & 2.9 & 64.6 & 2.0 & 0.1 & 2.3 & 1.8 & 0.3 & 0.0 & 14.8 & 12.5 & 0.20 & 2.9 \\
\hline A538-1 & 0.1 & 0.7 & 8.9 & 15.9 & 2.8 & 64.8 & 1.9 & 0.1 & 2.2 & 2.2 & 0.4 & 0.1 & 15.0 & 12.9 & 0.19 & 3.0 \\
\hline A16-2 & 0.1 & 1.3 & 8.1 & 19.9 & 3.2 & 61.6 & 1.4 & 0.1 & 2.2 & 1.7 & 0.3 & 0.1 & 15.3 & 11.4 & 0.25 & 2.5 \\
\hline HAES849 & 0.1 & 0.9 & 9.2 & 17.8 & 3.0 & 63.7 & 1.5 & 0.1 & 2.0 & 1.4 & 0.2 & 0.1 & 15.4 & 12.7 & 0.22 & 2.7 \\
\hline HAES246-2 & 0.1 & 1.0 & 9.5 & 18.0 & 2.5 & 62.2 & 2.0 & 0.1 & 2.1 & 2.0 & 0.3 & 0.1 & 15.6 & 13.4 & 0.22 & 2.6 \\
\hline HAES344-1 & 0.1 & 1.4 & 8.6 & 21.0 & 2.9 & 60.0 & 1.4 & 0.0 & 2.0 & 1.8 & 0.5 & 0.2 & 15.6 & 11.5 & 0.27 & 2.3 \\
\hline HAES842 & 0.0 & 0.6 & 9.0 & 18.2 & 3.5 & 61.5 & 1.6 & 0.1 & 2.6 & 2.0 & 0.6 & 0.1 & 16.3 & 9.8 & 0.22 & 2.7 \\
\hline HAES246-1 & 0.1 & 0.9 & 10.3 & 17.1 & 3.0 & 62.1 & 1.6 & 0.1 & 2.3 & 2.0 & 0.3 & 0.1 & 17.0 & 11.7 & 0.21 & 2.6 \\
\hline
\end{tabular}

Total sat-fat $=$ sum of individual saturated fatty acids; $\mathrm{C} 18$-desat $=\mathrm{C} 18$ desaturation partitioning ratio; $\mathrm{C} 16$-desat $=\mathrm{C} 16$ desaturation partitioning ratio; $\mathrm{C} 16$ elong $=$ C16 elongation partitioning ratio.

Table 2. Kernel oil fatty acid profiles and desaturation/elongation partitioning ratios of breeding accessions. The number following the cultivar or accession name is the tree number.

Fatty acid (\%)

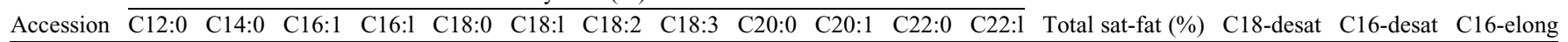

\begin{tabular}{|c|c|c|c|c|c|c|c|c|c|c|c|c|c|c|c|c|}
\hline$\overline{\mathrm{S}-1}$ & 0.1 & 0.7 & 7.6 & 17.8 & 2.1 & 66.0 & 1.8 & 0.1 & 1.7 & 2.0 & 0.2 & 0.1 & 12.3 & 17.6 & 0.22 & 2.9 \\
\hline $\mathrm{T}-2$ & 0.1 & 0.7 & 7.5 & 22.1 & 2.2 & 62.0 & 1.5 & 0.1 & 1.8 & 1.7 & 0.2 & 0.0 & 12.6 & 15.5 & 0.29 & 2.3 \\
\hline E-1 & 0.1 & 0.6 & 7.8 & 18.0 & 1.8 & 65.7 & 1.6 & 0.1 & 1.7 & 1.9 & 0.5 & 0.1 & 12.6 & 17.0 & 0.22 & 2.8 \\
\hline L-1 & 0.1 & 0.8 & 7.9 & 16.8 & 1.8 & 64.5 & 2.8 & 0.1 & 1.9 & 2.9 & 0.3 & 0.1 & 12.7 & 18.0 & 0.20 & 3.0 \\
\hline H-2 & 0.1 & 1.4 & 7.2 & 21.3 & 2.1 & 63.6 & 1.0 & 0.1 & 1.6 & 1.2 & 0.2 & 0.0 & 12.7 & 16.4 & 0.28 & 2.5 \\
\hline D-2 & 0.1 & 0.8 & 7.7 & 16.4 & 2.1 & 66.0 & 2.1 & 0.1 & 1.7 & 2.2 & 0.6 & 0.2 & 13.1 & 15.7 & 0.20 & 3.1 \\
\hline B-1 & 0.1 & 0.9 & 7.5 & 18.5 & 2.4 & 64.8 & 1.6 & 0.1 & 1.7 & 1.8 & 0.5 & 0.1 & 13.1 & 15.0 & 0.23 & 2.8 \\
\hline $\mathrm{F}-2$ & 0.0 & 0.6 & 8.4 & 16.5 & 2.2 & 66.4 & 2.0 & 0.1 & 1.8 & 1.6 & 0.4 & 0.1 & 13.4 & 16.2 & 0.20 & 3.0 \\
\hline $0-2$ & 0.0 & 0.3 & 7.5 & 18.8 & 3.2 & 65.2 & 1.2 & 0.1 & 2.0 & 1.3 & 0.4 & 0.1 & 13.4 & 12.1 & 0.23 & 2.8 \\
\hline $\mathrm{T}-1$ & 0.1 & 0.8 & 8.8 & 24.5 & 1.9 & 58.9 & 1.3 & 0.1 & 1.6 & 1.6 & 0.3 & 0.0 & 13.6 & 16.1 & 0.33 & 2.0 \\
\hline $1-1$ & 0.1 & 1.1 & 8.0 & 19.7 & 2.2 & 63.1 & 1.7 & 0.1 & 1.9 & 1.7 & 0.3 & 0.0 & 13.6 & 15.1 & 0.25 & 2.6 \\
\hline Q-2 & 0.0 & 0.6 & 8.8 & 16.8 & 2.1 & 65.2 & 2.4 & 0.1 & 1.7 & 1.8 & 0.5 & 0.2 & 13.6 & 16.4 & 0.20 & 2.9 \\
\hline N-1 & 0.1 & 0.8 & 7.9 & 20.8 & 2.6 & 62.3 & 1.6 & 0.1 & 1.9 & 1.4 & 0.4 & 0.1 & 13.7 & 13.4 & 0.27 & 2.4 \\
\hline $0-1$ & 0.1 & 0.9 & 8.4 & 18.0 & 2.1 & 63.3 & 2.7 & 0.1 & 1.8 & 2.2 & 0.3 & 0.1 & 13.7 & 16.0 & 0.22 & 2.7 \\
\hline $6-1$ & 0.1 & 1.1 & 8.7 & 22.3 & 1.9 & 61.5 & 1.0 & 0.1 & 1.5 & 1.3 & 0.4 & 0.1 & 13.7 & 16.9 & 0.29 & 2.2 \\
\hline $\mathrm{R}$ & 0.1 & 1.0 & 8.0 & 18.7 & 2.3 & 63.3 & 1.8 & 0.1 & 2.0 & 2.3 & 0.3 & 0.1 & 13.8 & 14.4 & 0.23 & 2.7 \\
\hline C-1 & 0.0 & 0.7 & 7.7 & 19.3 & 3.1 & 63.2 & 2.0 & 0.1 & 2.0 & 1.6 & 0.3 & 0.0 & 13.8 & 12.3 & 0.24 & 2.7 \\
\hline $0-1$ & 0.0 & 0.5 & 7.8 & 21.3 & 3.0 & 61.2 & 1.7 & 0.1 & 2.3 & 1.8 & 0.2 & 0.1 & 13.9 & 11.6 & 0.27 & 2.4 \\
\hline G-2 & 0.1 & 0.6 & 8.7 & 24.0 & 2.5 & 58.7 & 1.7 & 0.1 & 1.7 & 1.5 & 0.4 & 0.1 & 14.0 & 13.5 & 0.32 & 2.0 \\
\hline B-2 & 0.1 & 1.3 & 7.6 & 21.0 & 2.8 & 61.8 & 1.4 & 0.1 & 1.9 & 1.7 & 0.2 & 0.1 & 14.0 & 13.2 & 0.27 & 2.4 \\
\hline F-1 & 0.1 & 0.6 & 8.2 & 14.5 & 2.9 & 67.3 & 2.3 & 0.1 & 2.0 & 1.6 & 0.2 & 0.1 & 14.1 & 13.9 & 0.17 & 3.4 \\
\hline C-2 & 0.1 & 0.8 & 7.6 & 20.2 & 3.1 & 61.9 & 1.8 & 0.1 & 2.3 & 1.8 & 0.3 & 0.1 & 14.1 & 11.6 & 0.26 & 2.6 \\
\hline P-1 & 0.1 & 0.8 & 7.5 & 18.7 & 3.2 & 63.4 & 1.7 & 0.1 & 2.2 & 1.9 & 0.4 & 0.1 & 14.1 & 11.7 & 0.23 & 2.8 \\
\hline D-1 & 0.1 & 0.9 & 8.0 & 17.2 & 2.7 & 64.9 & 1.5 & 0.1 & 2.0 & 1.9 & 0.7 & 0.2 & 14.3 & 12.9 & 0.21 & 2.9 \\
\hline H-1 & 0.1 & 0.8 & 7.5 & 17.6 & 3.2 & 63.5 & 2.6 & 0.1 & 2.4 & 1.8 & 0.3 & 0.0 & 14.3 & 11.4 & 0.22 & 2.9 \\
\hline E-2 & 0.1 & 0.6 & 8.5 & 18.2 & 2.7 & 63.2 & 2.3 & 0.1 & 2.2 & 1.8 & 0.2 & 0.0 & 14.3 & 13.0 & 0.22 & 2.7 \\
\hline L-2 & 0.1 & 0.7 & 8.4 & 24.2 & 2.6 & 57.5 & 1.7 & 0.1 & 2.2 & 2.1 & 0.4 & 0.1 & 14.4 & 11.8 & 0.32 & 2.0 \\
\hline P-2 & 0.1 & 0.7 & 7.5 & 19.1 & 3.5 & 63.0 & 1.6 & 0.1 & 2.5 & 1.8 & 0.2 & 0.0 & 14.4 & 10.8 & 0.24 & 2.7 \\
\hline $1-2$ & 0.1 & 1.0 & 7.5 & 17.4 & 3.1 & 64.9 & 2.2 & 0.1 & 2.2 & 0.8 & 0.6 & 0.2 & 14.4 & 11.6 & 0.21 & 3.0 \\
\hline J-1 & 0.0 & 0.5 & 8.7 & 15.5 & 2.6 & 65.3 & 2.4 & 0.1 & 2.1 & 2.1 & 0.6 & 0.1 & 14.5 & 13.4 & 0.18 & 3.1 \\
\hline A-2 & 0.1 & 0.8 & 8.4 & 16.4 & 2.6 & 64.5 & 2.4 & 0.1 & 2.0 & 1.9 & 0.7 & 0.2 & 14.5 & 13.1 & 0.20 & 3.0 \\
\hline $\mathrm{J}-2$ & 0.0 & 0.6 & 8.3 & 19.9 & 3.3 & 62.1 & 1.3 & 0.1 & 2.2 & 1.7 & 0.3 & 0.1 & 14.8 & 11.1 & 0.25 & 2.5 \\
\hline M-2 & 0.1 & 1.0 & 8.0 & 21.7 & 3.3 & 60.3 & 1.3 & 0.1 & 2.1 & 1.5 & 0.6 & 0.1 & 15.1 & 10.6 & 0.28 & 2.3 \\
\hline N-2 & 0.1 & 1.2 & 8.0 & 17.0 & 2.8 & 63.5 & 2.3 & 0.1 & 2.3 & 1.9 & 0.7 & 0.1 & 15.1 & 11.7 & 0.21 & 3.0 \\
\hline A-1 & 0.1 & 0.8 & 8.7 & 13.8 & 3.1 & 67.4 & 2.3 & 0.1 & 2.2 & 1.1 & 0.2 & 0.0 & 15.3 & 12.6 & 0.16 & 3.4 \\
\hline M-1 & 0.1 & 1.0 & 8.9 & 18.1 & 3.2 & 62.7 & 1.2 & 0.1 & 2.2 & 1.8 & 0.6 & 0.1 & 16.0 & 11.0 & 0.22 & 2.7 \\
\hline K-1 & 0.0 & 0.9 & 9.7 & 20.3 & 2.9 & 60.1 & 1.7 & 0.0 & 2.0 & 1.8 & 0.5 & 0.1 & 16.0 & 11.9 & 0.26 & 2.3 \\
\hline $\mathrm{K}-2$ & 0.1 & 1.0 & 9.3 & 20.6 & 3.3 & 59.3 & 1.9 & 0.1 & 2.3 & 1.8 & 0.3 & 0.1 & 16.2 & 10.8 & 0.26 & 2.3 \\
\hline S-2 & 0.1 & 1.0 & 7.8 & 19.1 & 4.3 & 60.6 & 2.0 & 0.1 & 2.8 & 1.6 & 0.5 & 0.2 & 16.4 & 8.5 & 0.24 & 2.7 \\
\hline
\end{tabular}

Total sat-fat $=$ sum of individual saturated fatty acids measured as a percentage; $\mathrm{C} 18$-desat $=\mathrm{C} 18$ desaturation partitioning ratio; $\mathrm{C} 16$-desat $=\mathrm{C} 16$ desaturation partitioning ratio; $\mathrm{C} 16$-elong $=\mathrm{C} 16$ elongation partitioning ratio. 
An estimate of $\mathrm{C} 16$ and $\mathrm{C} 18$ fatty acid desaturation and elongation partitioning ratios were calculated based on the ratios of different fatty acid groups found in the fatty acid profile. For example, the monounsaturated fatty acid C16:1 is formed (desaturated) from its saturated precursor C16:0. But, $\mathrm{C} 16: 0$ can also be elongated to $\mathrm{C} 18: 0$, which can be further elongated to $\mathrm{C} 20: 0$, or desaturated to $\mathrm{C} 18: 1$. Therefore, the ratio of $\mathrm{C} 16: 1$ to its precursor $\mathrm{C} 16: 0$, plus these other downstream fatty acids (C18:0, C20:0, C18:1, etc.), provides an indication of how well a particular accession partitions fatty acids toward C16:1. Similarly, an estimate can be made as to how well an accession partitions C18:0 toward C18:1, and how well C16:0 is elongated to C18:0. These calculations assume that plant fatty acids are formed principally through elongation and desaturation, rather than shortening or saturation. Regular fatty acid desaturation of $\mathrm{C} 16: 0$ to C16:1 and C18:0 to C18:1, and elongation of

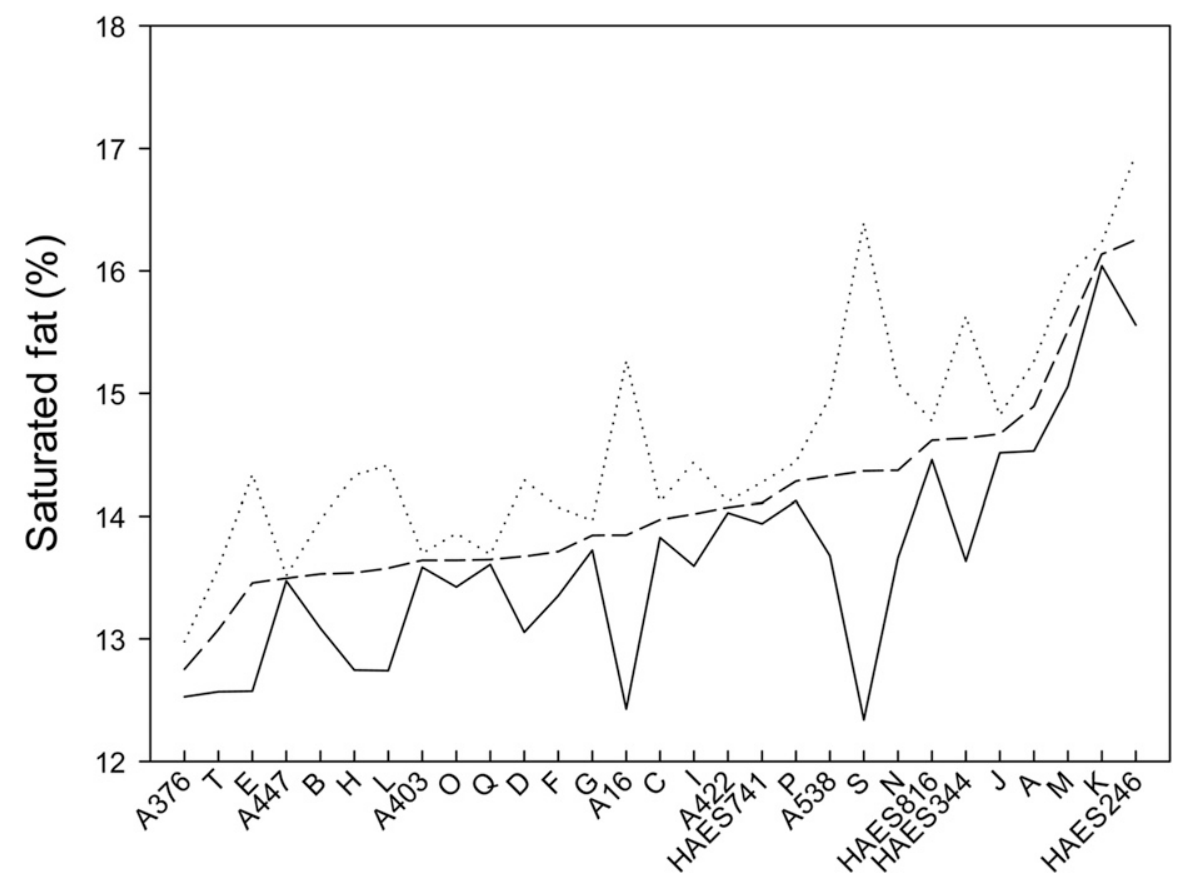

\section{Accession}

Fig. 1. Variation in total saturated fat content between two trees of the same cultivar/accession in different locations within the orchard. The midline (dashed) indicates the average of the two trees (upper and lower lines). Cultivars or accessions with only one tree are not shown.

Table 3. Linear regression relationships between total saturated fat (\%) and fatty acid desaturation and elongation partitioning ratios.

\begin{tabular}{lcc}
\hline Parameter & F significance & Coefficient of determination $\left(r^{2}\right)$ \\
\hline C16desat & NS & 0.01 \\
C18desat & $* * *$ & 0.52 \\
C16elong & NS & 0.01 \\
C16desat $\times$ C18desat & $* * *$ & 0.52 \\
C16desat $\times$ C16elong & $* * *$ & 0.47 \\
C18desat $\times$ C16elong & $* * *$ & 0.51 \\
C18desat $\times$ C16desat $\times$ C16elong & $* * *$ & 0.88 \\
\hline
\end{tabular}

Ns, ***Not significant or significant at $P \leq 0.001$, respectively.

C16-desat $=\mathrm{C} 16$ desaturation partitioning ratio; $\mathrm{C} 18$-desat $=\mathrm{C} 18$ desaturation partitioning ratio; $\mathrm{C} 16$ elong $=\mathrm{C} 16$ elongation partitioning ratio. partitioning ratios was conducted using Genstat statistical software (Version 18, VSN International, Hemel Hempstead, UK). Differences in fatty acid content between accessions were not compared statistically because of the low tree number within the orchard germplasm collection. Fatty acid data from a composite sample from each of two trees per accession were collected to generate partitioning ratios as well as an indication of potential intertree variation within a mixed orchard.

\section{Results}

The major fatty acids in all cultivars and breeding accessions were the monounsaturated fats: oleic acid (C18:1) and palmitoleic acid (C16:1). The concentration of oleic and palmitic acid ranged from $57 \%$ to $67 \%$ and $14 \%$ to $24 \%$, respectively. The next highest concentrated fatty acids were the saturated fats: palmitic acid $(\mathrm{C} 16: 0,7 \%$ to $10 \%)$, stearic acid (C18:0, 2\% to 4\%), and arachidic acid $(\mathrm{C} 20: 0,2 \%)$. The remaining unsaturated fatty acids (C18:2, C18:3, C20:1, and C22:1) were each generally less than $2 \%$ (Tables 1 and 2). In addition to the major saturated fatty acids, other saturated fats detected in macadamia included, in order of concentration, myristic acid (C14:0), behenic acid (C22:0), and lauric acid (C12:0).

Total saturated fatty acid concentration across the lines varied over a narrow range of $12.3 \%$ to $17.0 \%$ (Fig. 1), with an average of $14.2 \%$. The greatest average saturated fat percentage was observed in 'HAES246', whereas the least was observed in 'A376'. Different tree location of the same accession was also observed to have an impact on saturated fat concentration. Although in some cultivars and accessions ('A447', 'A403', Q, 'A422') intertree variability was quite small at, for example, $0.1 \%$, in others (S, 'A 16 ') it was as high as $4.1 \%$.

As a simple comparison of desaturation efficiency, the partitioning ratio of unsaturated to saturated fat varied between fatty acids of different chain length. Across all accessions, the ratio of unsaturated palmitoleic acid (C16:1) to saturated palmitic acid (C16:0) was much less than the ratio of $\mathrm{C} 18$ unsaturated $(18: 1,18: 2, \mathrm{C} 18: 3)$ to saturated $(18: 0)$ fats (Tables 1 and 2). Consequently, palmitic acid (C16:0) was consistently the highest saturated fat present in all accessions. Desaturation of stearic acid (C18:0) to oleic acid (C18:1) appeared to be much more efficient.

Total saturated fat was found to be correlated to desaturation and elongation partitioning ratios. C18-desaturation partitioning, rather than C16-desaturation partitioning, was observed to account for a large percentage of variance $\left(r^{2}=52 \%\right)$ in total saturated fatty acids (Table 3). However, although C16-desaturation and C16-elongation partitioning accounted for less than $2 \%$ variance individually, combining C18-desaturation, C16-desaturation, and C16-elongation partitioning was able to explain $88 \%$ of variance of total saturated fat concentration (Table 3 ). Interestingly, C16-elongation partitioning correlated highly and negatively $\left(r^{2}=92 \%\right)$ 
with C16-desaturation partitioning (Fig. 2A). Consequently, the lowest total saturated fat values tended to be achieved with a combination of high $\mathrm{C} 18$-desaturation and high C16-elongation partitioning, or high C18desaturation with high C16-desatuation partitioning, but not both. C18-desaturation partitioning was also found to have no correlation with the C16-desaturation partitioning ratio (Fig. 2B).

\section{Discussion}

The fatty acid profiles observed in the accessions and cultivars assessed in the current trial indicated that total saturated fat varied within a narrow range of $12.3 \%$ to $17.0 \%$. The average was $14.2 \%$, which is similar to that published for macadamia oil in the Food Standards Australia and New Zealand (2017) nutrition tables. Because the lowest saturated fat concentration (i.e., $12.3 \%$ ) is only $13 \%$ less than the Food Standards Australia and New Zealand reference value of $14.2 \%$, this oil is insufficient to qualify as a "reduced" saturated fat product, which requires at least a $25 \%$ reduction relative to the reference value (Federal Register of Legislation, 2017). The current saturated fat content also slightly reduces the Australian "health star rating" relative to many other nuts (Front-of-Pack Labelling Secretariat, 2018). Similarly, on a wholekernel value, which consists of $75 \%$ oil, the amount of saturated fat $(4.6 \mathrm{~g} / 50 \mathrm{~g}$ kernel $)$ exceeds that required $(<4.0 \mathrm{~g} / 50 \mathrm{~g})$ by the U.S. Food and Drug Administration for an unqualified nut health claim possible for

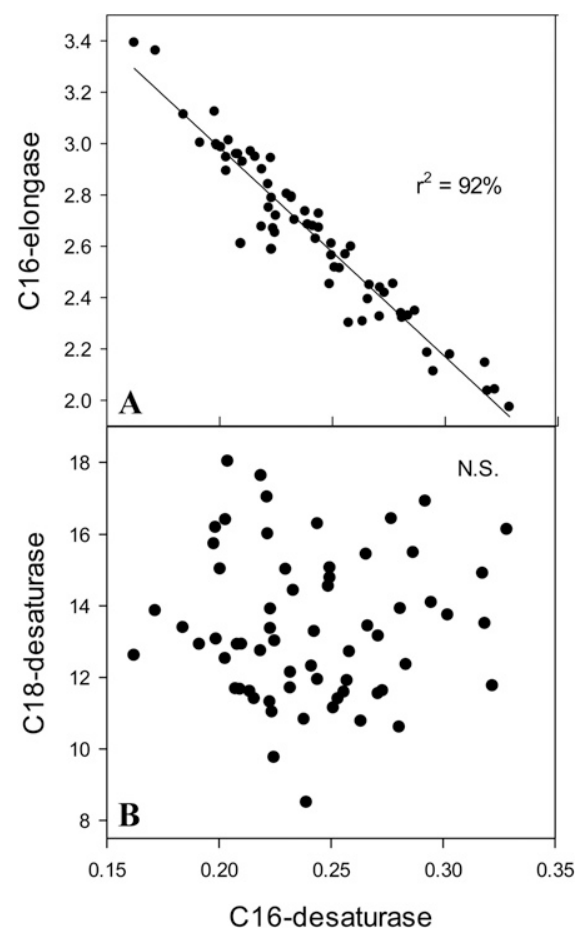

Fig. 2. Correlation relationships between (A) C16desaturase and C16-elongase, and (B) C18desaturase partitioning ratios. many other commercial nuts (e.g., almond, pistachio, peanut) (Food and Drug Administration, 2003). Clearly, assessment of other macadamia accessions, including those outside the M. integrifolia and $M$. tetraphylla species, or targeted breeding, is necessary to reach lower total saturated fat concentrations.

In agreement with previous reports (Aquino-Bolaños et al., 2017; Beuchat and Worthington, 1978; Carrillo et al., 2017; Cavaletto et al., 1966; Saleeb et al., 1973), palmitic (C16:0) and stearic acid (C18:0) were the major saturated fatty acids present in the breeding accessions/cultivars assessed. Palmitic acid always constituted the highest fatty acid, with about three times as much as stearic acid. From the data (Tables 1 and 2), it would appear that endogenous desaturation of palmitic to palmitoleic acid (C16:1) is considerably less efficient than stearic to oleic (C18:1). It was also apparent that desaturation partitioning of C16:0 was not at all correlated to desaturation partitioning of C18:0 (Fig. 2B), which would support the suggestion by Gummeson et al. (2000) that the enzyme responsible for $\mathrm{C} 18$ desaturation $(\Delta 9$ stearoyl-acyl-carrier-protein) is unlikely to be the enzyme responsible for $\mathrm{C} 16$ desaturation.

Total saturated fat content was found to correlate significantly with the $\mathrm{C} 18$ desaturase partitioning ratio $\left(r^{2}=52 \%\right)$, but correlated poorly with either C16-desaturase or C16-elongase partitioning ratios (Table 3). This is probably the result of the generally greater conversion of $\mathrm{C} 18: 0$ to $\mathrm{C} 18: 1$, and the fact that the denominator of this equation included only the desaturated fats (C18:0, C20:0, and C22:0), as $\mathrm{C} 20: 1$ and $\mathrm{C} 22: 1$ are thought to be formed via elongation of $\mathrm{C} 18: 1$ and $\mathrm{C} 20: 1$, respectively, rather than by direct desaturation of C20:0 and C22:0 (Barker et al., 2007).

Interestingly, addition of C16-desaturase and $\mathrm{C} 16$-elongation partitioning ratios to the correlation equation further accounted for the variation observed $\left(r^{2}=88 \%\right)$ in saturated fat content (Table 3). It would appear that accessions or cultivars with the lowest saturated fat content had 1) a combination of high C18-desaturation partitioning and high C16desaturation partitioning or 2) a combination of high C18-desaturation partitioning and high C16-elongation partitioning. Because C16-desaturation and C16-elongation partitioning ratios correlate strongly and negatively (Fig. 2A), it was impossible to have both in the same accession. This indicates that $\mathrm{C} 16$ desaturase and $\mathrm{C} 16$ elongase are competing for the same substrate (C16:0). Putting all three factors in the same equation accounted for both scenarios leading to lower total saturated fat.

Different saturated fatty acid profiles for trees of the same accession positioned at different locations within the orchard were also observed in the current trial (Fig. 1). It is possible that these differences were the result of different pollinizers for each tree. Macadamia has a strong tendency to outcross (Sedgley et al., 1990), and the kernel tissue is made up of genetic material from both the maternal and paternal genome. It is therefore likely that the pollinizer would modify the fatty acid profile of the maternal accession, although a controlled pollination trial would be necessary to confirm this. Such a situation should be taken into account when developing a reduced-saturated fat or increasedunsaturated fat breeding line. In the current study, the pollinizers were not identified, although it is likely they may have been the adjacent flowering trees.

The current study indicates that saturated fat content in macadamia oil varies within the range of $12.3 \%$ to $17.0 \%$. The predominant saturated fatty acids, in order of concentration, were palmitic, stearic, and behenic acid. In general, desaturation of palmitic acid appeared less efficient than desaturation of stearic acid. Although the majority of lines with less saturated fat content had a combination of both higher C16- and higher C18desaturation partitioning ratios, some lines had a combination of higher C18-desaturation and higher C16-elongation partitioning ratios. Both combinations were able to achieve a lower saturated fat content as a result of the latter shifting the fatty acid flux toward C18:0, which appears to be desaturated more efficiently. Interestingly, the kernel fatty acid profile is likely to be affected by the pollinizer, which should be considered in future assessments. Development of a reduced-saturated fat macadamia will likely require both low-saturated fat maternal and paternal parents.

\section{Literature Cited}

Aquino-Bolaños, E.N., L. Mapel-Velazco, S.T. Martín-del-Campo, J.L. Chávez-Servia, A.J. Martínez, and I. Verdalet-Guzmán. 2017. Fatty acids profile of oil from nine varieties of macadamia nut. Intl. J. Food Prop. 20:12621269.

Barker, G.C., T.R. Larson, I.A. Graham, J.R. Lynn, and G.J. King. 2007. Novel insights into seed fatty acid synthesis and modification pathways from genetic diversity and quantitative trait loci analysis of the Brassica C genome. Plant Physiol. 144:1827-1842.

Beuchat, L. and R.E. Worthington. 1978. Fatty acid composition of tree nut oils. J. Food Technol. 13:355-358

Brown, A.P., A.R. Slabas, and J.B. Rafferty. 2009 Fatty acid biosynthesis in plants: Metabolic pathways, structure, and organization, p. 1134. In: H. Wada and N. Murata (eds.). Lipids in Photosynthesis. Springer, Dordrecht, Netherlands.

Carrillo, W., C. Carpio, D. Morales, E. Vilcacundo, and M. Alvarez. 2017. Fatty acids composition in macadamia seed oil (Macadamia integrifolia) from Ecuador. Asian J. Pharm. Clin. Res. 10:303-306.

Cavaletto, C.G., A. De la Cruz, E. Ross, and H.Y. Yamamoto. 1966. Factors affecting macadamia nut stability: 1. Raw kernels. Food Technol. 20:1084-1087.

Clifton, P.M. and J.B. Keogh. 2017. A systematic review of the effect of dietary saturated and polyunsaturated fat on heart disease. Nutr. Metab. Cardiovasc. Dis. 27:1060-1080.

Federal Register of Legislation. 2017. Australia New Zealand Food Standards Code: Schedule 4: Nutrition, health and related claims. $<$ https:// www.legislation.gov.au/Details/F2017C00711>. 
Food and Drug Administration. 2003. Qualified health claims: Letter of enforcement discretion: Nuts and coronary heart disease. Docket no. 02P-0505. <http://wayback.archive-it.org/ 7993/20171114183724/https://www.fda.gov/Food/ IngredientsPackagingLabeling/LabelingNutrition/ ucm072926.htm>.

Food and Drug Administration. 2017. Petition for a qualified health claim for macadamia nuts and reduced risk of coronary heart disease. Docket no. FDA-2015-Q-4850. < https://www.fda.gov/downloads/Food/LabelingNutrition/UCM568057.pdf $>$.

Food Standards Australia New Zealand. 2017. NUTTAB 2010 online searchable database: Oil, macadamia. Food ID: 04C10086. <http://www. foodstandards.gov.au/science/monitoringnutrients/nutrientables/nuttab/Pages/default. aspx $>$.

Front-of-Pack Labelling Secretariat. 2018. Guide for industry to the Health Star Rating Calculator, version 6 . <http://healthstarrating.gov.au/ internet/healthstarrating/publishing.nsf/Content/ E380CCCA07E1E42FCA257DA500196044/
\$File/Guide\%20for\%20Industry\%20to\%20the $\% 20$ Health $\% 20$ Star\%20Rating\%20Calculator. pdf $>$.

Gummeson, P.O., M. Lenman, M. Lee, S. Singh, and S. Stymneet. 2000. Characterisation of acyl-ACP desaturases from Macadamia integrifolia Maiden \& Betche and Nerium oleander L. Plant Sci. 154:53-60.

Harwood, J.L. 2018. Plant fatty acid biosynthesis. AOCS Lipid Library. < http://lipidlibrary.aocs.org/ Biochemistry/content.cfm? ItemNumber $=40304>$.

Mereles, L.G., E.A. Ferro, N.L. Alvarenga, S.B. Caballero, L.N. Wiszovaty, P.A. Piris, and B.J. Michajluk. 2017. Chemical composition of Macadamia integrifolia (Maiden and Betche) nuts from Paraguay. Intl. Food Res. J. 24:25992608.

Rodríguez, M.F.R., A. Sánchez-García, J.J. Salas, R. Garces, and E. Martínez-Force. 2015. Characterization of soluble acyl-ACP desaturases from Camelina sativa, Macadamia tetraphylla and Dolichandra unguis-cati. J. Plant Physiol. 178:35-42.
Ros, E. and J. Mataix. 2006. Fatty acid composition of nuts: Implications for cardiovascular health. Brit. J. Nutr. 96(Suppl. 2):S29-S35.

Sacks, F.M., A.H. Lichtenstein, J.H.Y. Wu, L.J. Appel, M.A. Creager, P.M. Kris-Etherton, M. Miller, E.B. Rimm, L.L. Rudel, J.G. Robinson, N.J. Stone, and L.V. Van Horn. 2017. Dietary fats and cardiovascular disease: A presidential advisory from the American Heart Association. Circulation 136:e1-e23.

Saleeb, W.F., D.M. Yermanos, C.K. Huszar, W.B. Storey, and C.K. Labanauskas. 1973. The oil and protein in nuts of Macadamia tetraphylla L. Johnson, Macadamia integrifolia Maiden and Betche, and their F1 hybrid. J. Amer. Soc. Hort. Sci. 98:453-456.

Sedgley, M., F.D.H. Bell, D. Bell, C.W. Winks, and S.J. Pattison. 1990. Self- and cross-compatibility of macadamia cultivars. J. Hort. Sci. 65:205-213.

Wang, D.D. and F.B. Hu. 2017. Dietary fat and risk of cardiovascular disease: Recent controversies and advances. Annu. Rev. Nutr. 37:423-446. 